\title{
Astrocytes have the capacity to act as antigen-presenting cells in the Parkinson's disease brain
}

Jinar Rostami ${ }^{1}$, Grammatiki Fotaki ${ }^{2}$, Julien Sirois ${ }^{3}$, Ropafadzo Mzezewa' ${ }^{1}$, Joakim Bergström¹, Magnus Essand ${ }^{2}$, Luke Healy ${ }^{3}$ and Anna Erlandsson ${ }^{1 *}$

\begin{abstract}
Background: Many lines of evidence suggest that accumulation of aggregated alpha-synuclein (aSYN) in the Parkinson's disease (PD) brain causes infiltration of T cells. However, in which ways the stationary brain cells interact with the T cells remain elusive. Here, we identify astrocytes as potential antigen-presenting cells capable of activating $T$ cells in the PD brain. Astrocytes are a major component of the nervous system, and accumulating data indicate that astrocytes can play a central role during PD progression.

Methods: To investigate the role of astrocytes in antigen presentation and T-cell activation in the PD brain, we analyzed post mortem brain tissue from PD patients and controls. Moreover, we studied the capacity of cultured human astrocytes and adult human microglia to act as professional antigen-presenting cells following exposure to preformed aSYN fibrils.

Results: Our analysis of post mortem brain tissue demonstrated that PD patients express high levels of MHC-II, which correlated with the load of pathological, phosphorylated aSYN. Interestingly, a very high proportion of the MHC-II co-localized with astrocytic markers. Importantly, we found both perivascular and infiltrated CD4 ${ }^{+} \mathrm{T}$ cells to be surrounded by MHC-II expressing astrocytes, confirming an astrocyte T cell cross-talk in the PD brain. Moreover, we showed that aSYN accumulation in cultured human astrocytes triggered surface expression of co-stimulatory molecules critical for T-cell activation, while cultured human microglia displayed very poor antigen presentation capacity. Notably, intercellular transfer of aSYN/MHC-II deposits occurred between astrocytes via tunneling nanotubes, indicating spreading of inflammation in addition to toxic protein aggregates.
\end{abstract}

Conclusions: In conclusion, our data from histology and cell culture studies suggest an important role for astrocytes in antigen presentation and T-cell activation in the PD brain, highlighting astrocytes as a promising therapeutic target in the context of chronic inflammation.

Keywords: Astrocytes, T-cell infiltration, MHC-II, Antigen presentation, Alpha-synuclein, Parkinson's disease, Tunneling nanotubes

\footnotetext{
* Correspondence: anna.erlandsson@pubcare.uu.se

'Molecular Geriatrics, Department of Public Health and Caring Sciences/

Molecular Geriatrics, Rudbeck Laboratory, Uppsala University, SE-751 85

Uppsala, Sweden

Full list of author information is available at the end of the article
}

(C) The Author(s). 2020 Open Access This article is licensed under a Creative Commons Attribution 4.0 International License, which permits use, sharing, adaptation, distribution and reproduction in any medium or format, as long as you give appropriate credit to the original author(s) and the source, provide a link to the Creative Commons licence, and indicate if changes were made. The images or other third party material in this article are included in the article's Creative Commons licence, unless indicated otherwise in a credit line to the material. If material is not included in the article's Creative Commons licence and your intended use is not permitted by statutory regulation or exceeds the permitted use, you will need to obtain permission directly from the copyright holder. To view a copy of this licence, visit http://creativecommons.org/licenses/by/4.0/. The Creative Commons Public Domain Dedication waiver (http://creativecommons.org/publicdomain/zero/1.0/) applies to the data made available in this article, unless otherwise stated in a credit line to the data. 


\section{Background}

Parkinson's disease (PD) is a progressive neurodegenerative disorder with complex pathophysiology that develops over decades. The main characteristics of PD are intracellular deposits of aggregated $\alpha \mathrm{SYN}$ and chronic neuroinflammation $[1,2]$. Nonetheless, the interplay between these two processes and their respective impact on disease progression remain elusive. A recent study showed that $\mathrm{CD}^{+} \mathrm{T}$ helper cells derived from $\mathrm{PD}$ patients recognize $\alpha S Y N$ fibrils as an antigen [3]. In accordance, the presence of infiltrating $\mathrm{T}$ cells has been confirmed in animal models of PD as well as in post mortem brain tissues of PD patients [4-6]. However, which cell types that act as antigen-presenting cells (APCs) in the PD brain and activate the infiltrating $\mathrm{CD} 4^{+} \mathrm{T}$ cells remain unclear.

Astrocytes, the most numerous glial cell type in the central nervous system, are crucial for maintaining brain homeostasis, but are also highly involved in neuroinflammation [7]. In the PD brain, astrocytes are converted to a reactive, inflammatory state in which they phagocytose aggregated proteins and cell debris as well as secrete various cytokines and chemokines [8, 9]. Moreover, $\alpha S Y N$ deposits appear frequently in astrocytes at all disease stages [10-14]. We have previously demonstrated that $\alpha \mathrm{SYN}$ accumulation in cultured human astrocytes result in severe cellular stress, indicated by lysosomal, mitochondrial, and endoplasmic reticulum deficiencies. The stressed astrocytes respond by sending out tunneling nanotubes, enabling intercellular transfer of $\alpha \mathrm{SYN}$ inclusions to nearby cells, indicating astrocytes as crucial players in the progression of PD pathology $[15,16]$.

All nucleated cells in the body express major histocompatibility class I (MHC-I) for presentation of antigenic peptides to $\mathrm{CD}^{+} \mathrm{T}$ cells, while so called antigenpresenting cells (APCs) also express MHC class II (MHCII), enabling them to present antigenic peptides to $\mathrm{CD}_{4}^{+}$ helper T cells. Dendritic cells (DCs), B cells, and macrophages are considered classical or professional APCs as they also express the co-stimulatory molecules, including CD80, CD86, and CD40, that are required for activation of $\mathrm{CD}^{+} \mathrm{T}$ cells and $\mathrm{CD} 4^{+} \mathrm{T}$ cells [17]. The cell surface expression of the co-stimulatory factors by the professional APCs can for example be induced by the cytokine interferon-gamma (IFNY). APCs degrade ingested antigens via the endo-lysosomal pathway and digest the antigen to smaller fragments that are presented on MHC-II. It is believed that DCs are required for activation of naive $\mathrm{T}$ cells and a cytolytic T-cell mediated immune response as they can also cross-present exogenously ingested peptides on their MHC-I for activation of $\mathrm{CD}^{+} \mathrm{T}$ cells. Another feature of professional APCs is their ability to cross-talk and transfer MHC-II molecules between each other via cell-to-cell transfer [18].
For decades, there has been a debate whether APCs are present in the brain. Microglial cells arise from the yolk sac and invade the brain during embryonic development. They have been considered to be the resident CNS macrophages and consequently presumed to be the most likely brain APCs. However, several studies indicate that microglia are in fact poor antigen presenters [19-21]. Our previous observations that human astrocytes accumulate and transfer aggregated $\alpha \mathrm{SYN}$ raised the question whether infiltrating $\mathrm{T}$ cells interact with the $\alpha S Y N$ containing astrocytes and if the astrocytes can act as APCs in the PD brain. Hence, the aim with the present study was to investigate the role of $\alpha \mathrm{SYN}$ accumulating astrocytes in the chronic neuroinflammation in $\mathrm{PD}$, in regards to the adaptive immunity.

\section{Materials and methods Immunohistochemistry Deparaffinization}

Brain sections from mesencephalon and striatum of 10 PD patients and 10 controls (Table 1) were used (kindly provided from Uppsala Biobank by Professor Irina Alafuzoff, ethical number 2012/494). The thickness of the analyzed sections was $5 \mu \mathrm{m}$. To insure that exactly the same region was analyzed from all patients and controls, a cutting mold was used during the sectioning procedure. Prior to immunostaining, the sections were deparaffinized using xylene $2 \times$ for $10 \mathrm{~min}$, rehydrated using $99.5 \%$ ethanol $2 \times$ for $10 \mathrm{~min}, 95 \%$ ethanol for $10 \mathrm{~min}$, and $70 \%$ ethanol for $10 \mathrm{~min}$ and washed in PBS $3 \times 5 \mathrm{~min}$.

\section{Antigen retrieval and permeabilization}

Antigen retrieval was performed by boiling the samples in citric acid at $\mathrm{pH} 6$ for $2 \mathrm{~min}$ in $550 \mathrm{~W}$. The samples were left to cool down in room temperature (RT) for 20-30

Table 1 Sex, age, and post mortem fixation time of the 10 PD patients and the 10 controls analyzed in this study

\begin{tabular}{|c|c|c|c|c|c|}
\hline \multicolumn{3}{|l|}{ PD } & \multicolumn{3}{|l|}{ Control } \\
\hline Sex & Age & $\begin{array}{l}\text { Post mortem } \\
\text { fixation time } \\
\text { (weeks) }\end{array}$ & Sex & Age & $\begin{array}{l}\text { Post mortem } \\
\text { fixation time } \\
\text { (weeks) }\end{array}$ \\
\hline Male & 83 & 6 & Male & 72 & 4 \\
\hline Male & 84 & 4 & Male & 67 & 4 \\
\hline Male & 74 & 4 & Male & 72 & 5 \\
\hline Male & 77 & 3 & Male & 71 & 3 \\
\hline Male & 89 & 3 & Male & 68 & 5 \\
\hline Male & 74 & 3 & Male & 61 & 5 \\
\hline Male & 81 & 4 & Male & 75 & 5 \\
\hline Male & 79 & 5 & Female & 77 & 5 \\
\hline Female & 80 & 5 & Female & 61 & 6 \\
\hline Female & 78 & 4 & Female & 75 & 6 \\
\hline
\end{tabular}


min before permeabilization with $0.4 \%$ triton for $20 \mathrm{~min}$. Endogenous peroxidase was blocked with $1 \% \mathrm{H}_{2} \mathrm{O}_{2}$ (Thermo Fischer) for $30 \mathrm{~min}$ and blocked with TNB blocking buffer $(0.1 \mathrm{M}$ Tris- $\mathrm{HCl}$ and $0.15 \mathrm{M} \mathrm{NaCl}$ and 0.5\% blocking reagent FP1020, Perkin Elmer) for $30 \mathrm{~min}$.

\section{Primary antibody incubation}

Primary antibodies were prepared in PBS and incubated with the sections at $4{ }^{\circ} \mathrm{C}$ overnight. The primary antibodies used were HLADR/DP/DQ (DAKO M0775, 1:200), glial fibrillary acidic protein (GFAP, Abcam ab4674, 1: 500), ionized calcium-binding adaptor molecule 1 (Iba1, Abcam ab178846, 1:400), glutamate aspartate transporter (GLAST, Novus biologicals NB100-1869, 1:400) phosphorylated ser $129 \alpha$ SYN (p- $\alpha$ SYN) (Abcam ab 51253, 1: 500), Clone 42 (BD Biosciences, 610787, 1:200), and CD4 (Abcam ab133616, 1:100). The following day, the sections were washed in PBS $3 \times 5 \mathrm{~min}$.

\section{Secondary antibody incubation}

For the tyramide signal amplification kit (TSA), HRPconjugated secondary antibodies were used. A maximum of three primary antibodies were used for one staining, and the sections were incubated with one secondary antibody at the time for $1 \mathrm{~h}$ at RT. Thereafter, the sections were washed in PBS $3 \times 5 \mathrm{~min}$. For development, TSA reagent coupled with either Cy3.5 FITC or Cy5 (Perkin Elmer, 1:100 in amplification buffer) was added to the tissue sections for $15 \mathrm{~min}$ at RT in the dark. Before incubation with the next secondary antibody, the HRP activation from the previous staining was abolished using $0.4 \%$ sodium azide for $10 \mathrm{~min}$, followed by washes and incubation with $1 \% \mathrm{H}_{2} \mathrm{O}_{2}$ for $15 \mathrm{~min}$. The sections were blocked with TNB blocking buffer for $30 \mathrm{~min}$. After incubation and development of all secondary antibodies, the sections were dipped in $70 \%$ ethanol five times, incubated in $0.3 \%$ Sudan black for $20 \mathrm{~min}$, dipped in $70 \%$ ethanol twelve times, washed in PBS, and mounted using EverBrite Hardset mounting medium (Bionordika).

\section{Production of aSYN fibrils Generation}

Endotoxin-free recombinant human $\alpha S Y N$ (Anaspec A5555-1000) was resolved in sterile PBS to a concentration of $5 \mathrm{mg} / \mathrm{ml}$ and incubated on a shaker (IKA MS3 Basic, $1000 \mathrm{rpm}$ ) at $37^{\circ} \mathrm{C}$ for 7 days to form $\alpha S Y N$ preformed fibrils $(\alpha S Y N-F)$. Thereafter, the $\alpha S Y N-F$ were diluted to a working concentration of $2 \mathrm{mg} / \mathrm{ml}(140 \mu \mathrm{M})$ and left in $-70^{\circ} \mathrm{C}$ until use.

\section{Characterization}

The $\alpha S Y N-F$ were characterized using centrifugation, Thioflavin $\mathrm{T}$ (ThT) assay, and electron microscopy (EM). A short centrifugation at $\times 16,000 \mathrm{~g}$ for $5 \mathrm{~min}$ was performed to ensure pellet formation of insoluble, large fibrils. ThT solution $(100 \mu \mathrm{M})$ was added to recombinant monomers $(\alpha S Y N-M)$ (diluted 1:100 from $2 \mathrm{mg} / \mathrm{ml}$ in PBS), $\alpha$ SYN-F (diluted 1:100 from $2 \mathrm{mg} / \mathrm{ml}$ in PBS), and read instantly at a wave length of $420 \mathrm{~nm}$. For electron microscopy, $\alpha S Y N-M, \alpha S Y N-F$, and sonicated $\alpha S Y N-F$ (all diluted 1:5 in PBS) were dropped onto carbon coated 300 -mesh copper grids, negatively stained with $1 \%$ uranyl acetate for $5 \mathrm{~min}$ and air dried. The samples were analyzed using a Hitachi H-7100 transmission electron microscope.

\section{Cy3 labeling}

$\alpha$ SYN-F and $\alpha S Y N-M$ were labeled with $\mathrm{Cy} 3^{\mathrm{AM}}$ antibody labeling kit (GE Healthcare, PA33000) for $1 \mathrm{~h}$, according to the manufacture's protocol. To remove the unbound $\mathrm{Cy} 3$, the $\alpha \mathrm{SYN}-\mathrm{F}$ were centrifuged at $\times 23,000 \mathrm{~g}$ for 30 $\mathrm{min}$, the supernatant was removed, and the pellet was resolved in sterile PBS. The washing procedure was repeated three times.

\section{Sonication}

$\alpha$ SYN-F were diluted 1:2 in sterile PBS and sonicated in $20 \%$ amplitude, $1 \mathrm{~s}$ off and $1 \mathrm{~s}$ on for $30 \mathrm{~s}$ using a Sonics Vibra Cell sonicator, immediately prior to the experiment.

\section{Culture of human astrocytes}

Human embryonic stem cell (ESC)-derived astrocytes [22] were expanded in Advanced DMEM/F12 (Thermo Fischer 12634-010) supplemented with $20 \mathrm{ng} / \mathrm{ml}$ Human Ciliary Neurotrophic Factor (CNTF) (Thermo Fischer), $1 \%$ penicillin streptavidin (Thermo Fischer 15140-122), 1\% B27 supplement (Thermo Fischer 17504-044), 1\% non-essential amino acids (Merc Millipore TMS001-C), and 1\% L-glutamine (Thermo Fischer 25030-024). Cells were passaged using Trypsin-EDTA (Life technologies). Two weeks prior to the experiments, the media was changed to Neurobasal medium supplemented with $20 \mathrm{ng} / \mathrm{ml}$ CNTF, $1 \%$ penicillin streptavidin, $1 \%$ non-essential amino acids, 1\% L-glutamine (Thermo Fischer 25030-024), and N2 supplements (Thermo Fischer 17502048). For experiments, the astrocytes were seeded at a concentration of $4500 \mathrm{cells} / \mathrm{cm}^{2}$, resulting in a $40-50 \%$ confluence. Cells from 90 DIV to 120 DIV were used in the study.

\section{Isolation and culture of adult human microglia}

Human adult microglia were isolated as described previously [23] (ethical number ANTJ 1988/3). Shortly, human brain tissue was obtained from the temporal lobe of three epilepsy patients undergoing surgery. A separate microglia culture was derived from each donor. The tissue was washed in PBS several times, and blood clots were removed using a Pasteur pipette. The tissue was then incubated with $0.5 \%$ trypsin and $25 \mu \mathrm{g} / \mathrm{ml}$ of DNase in 
PBS on shake for $30 \mathrm{~min}$ at $37^{\circ} \mathrm{C}$. The trypsin was inactivated using $10 \%$ fetal calf serum (FCS), and the tissue was dissociated using a mashing filter prior to centrifugation at $1200 \mathrm{rpm}$ for $10 \mathrm{~min}$. Thereafter, the cells and debris were resuspended in PBS and added to Percoll before centrifugation at $\times 31,000 \mathrm{~g}$ for $30 \mathrm{~min}$ with no breaks at $4{ }^{\circ} \mathrm{C}$. The top layer containing myelin was removed, and the middle layer consisting of microglia and oligodendrocytes was resuspended in PBS and centrifuged at $1200 \mathrm{rpm}$ for $10 \mathrm{~min}$. The cells were counted and cultured at a density of $2 \times 10^{6}$ cells $/ \mathrm{ml}$ in a T12.5 flask in MEM medium supplemented with $5 \%$ FCS, $0.1 \%$ glucose, $1 \%$ penicillin-streptomycin, and $1 \%$ glutamine. Following day, the floating cells (which are oligodendrocytes) were removed. The cells were passaged using $0.05 \%$ trypsin and $2 \mathrm{mM}$ EDTA and cultured at a density of 50,000 cells $/ \mathrm{cm}^{2}$ for experiment.

\section{Astrocytes and microglia exposure to aSYN-F, aSYN-M and IFNY}

Astrocyte and microglia cultures were exposed to $0.5 \mu \mathrm{M}$ sonicated $\alpha \mathrm{SYN}-\mathrm{F}$ (Cy3 labeled or unlabeled), IFNY (Thermo Fischer $100 \mathrm{U} / \mathrm{ml}$ for astrocytes and 25 $\mathrm{U} / \mathrm{ml}$ for microglia), $0.5 \mu \mathrm{M} \alpha \mathrm{SYN}-\mathrm{F}+\mathrm{IFN} \gamma$, and $0.5 \mu \mathrm{M}$ $\alpha \mathrm{SYN}-\mathrm{M}$ or were left untreated. After 7 days of exposure the cells were fixed or detached for further analyses.

\section{Immunocytochemistry}

Cells were fixed in $4 \%$ paraformaldehyde (PFA) in PBS and washed with PBS. Blocking and permeabilization were performed with $5 \%$ normal goat serum (NGS) and $0.1 \%$ triton in PBS for 30 min in RT. Primary antibodies were diluted in $0.5 \%$ NGS and $0.1 \%$ triton in PBS and added to the cells for $2 \mathrm{~h}$ at RT. Thereafter, cells were washed 3 times with PBS prior to incubation with secondary antibodies or dyes for $1 \mathrm{~h}$ at RT. After additional washes, the cells were mounted, using Ever Brite Hardset Mounting medium with or without DAPI (BioNordika). The cells were analyzed using the fluorescence microscope Observer and Z1 Zeiss and confocal images were taken using Zeiss LSM700. The primary antibodies used were CD68 (DAKO, m0841, Clone KP1, 1:200), MHC-II (DAKO M0775, 1:200), MHC-I (Abcam EMR85 1:100), PDL1-1 (Novus biologicals NBP-176769 1:200), LAMP-1 (Abcam ab24170 1:200), nestin (Millipore ABD69 1:200), vimentin (Millipore AB5733 1:200), GLAST (Novus biologicals NB100-1869 1:400), and ALDH1L1 (Novus biologicals NBP2-24143 1:400). The secondary antibodies and dyes used were Alexaflour 488 goat anti rabbit/mouse (Thermo Fischer, 1:200) and Alexaflour 555 goat anti rabbit/mouse (Thermo Fischer, 1:200). To stain the plasma membrane, cells were incubated with wheat germ agglutinin and Alexa Fluor ${ }^{\circ} 350$ Conjugate (Life technologies, 1:200) for $10 \mathrm{~min}$.

\section{Flow cytometry on astrocytes}

The cells were detached using Accutase (Thermo Fischer) and centrifuged in $\times 300 g$ for $5 \mathrm{~min}$. The pelleted cells were resuspended in staining buffer containing 2\% FBS (BD Biosciences) and Versen (Thermo Fishcer) (1:1), before incubation with antibodies for $20 \mathrm{~min}$ in the dark. The following antibodies from BD Biosciences were used according to manufacturer's instructions: APC mouse anti-human CD40 (555591), BV510 mouse anti-human CD80 (563084), PE mouse anti-human CD86 (555665), FITC mouse anti-human HLADR/DP/DQ (555558), PECy7 mouse anti-human HLA-A/B/C (561349), and BV421 mouse anti-human PDL-1 (563738). The cells were washed and resuspended in Versen, and the fluorescence signal was examined with the machine flow cytometry Canto II (BD Biosciences). The flow cytometry data was analyzed using the FlowJo software (version 7.6.5; Tree Star, Ashland, OR) software.

\section{Flow cytometry on microglia}

Microglia cultures were detached using Accutase (Thermo Fischer) and centrifuged at $\times 300 \mathrm{~g}$ for $5 \mathrm{~min}$. The cells were incubated in blocking buffer (PBS, 10\% normal human serum and normal mouse IgG $(3 \mathrm{mg} / \mathrm{ml}))$ for $30 \mathrm{~min}$ and centrifuged at $\times 300 \mathrm{~g}$ for $5 \mathrm{~min}$, before incubation with the antibodies for $20 \mathrm{~min}$ in the dark. The following antibodies from BD Biosciences were used according to the manufacturer's instructions: APC mouse anti-human CD86 (BD Biosciences; 555660), FITC mouse anti-human HLA-DR/DP/DQ (BD Biosciences; 555558), BV786 mouse anti-human CD80 (BD Biosciences; 564159), PerCp mouse anti-human CD40 (Biolegend; 334316), and BV650 mouse anti-human HLA-A/B/C (BD Biosciences; 740407). The cells were washed and resuspended in $2 \mathrm{mM}$ EDTA in PBS, and the fluorescence signal was examined and analyzed using the FACSAria Fusion (BD Biosciences). The data was analyzed using the FlowJo software (version 7.6.5; Tree Star, Ashland, OR) software.

\section{Statistical analyses Immunohistochemistry}

For the MHC-II/GFAP/Iba1 immunostainings, mesencephalon and striatum sections from 10 PD patients and 10 controls were analyzed (Table 1). For the MHC-II/ GLAST immunostainings, mesencephalon sections from 10 PD patients and 10 controls were analyzed. Forty images were captured from each sample and region.

MHC-II-integrated density measurement, correlation between mesencephalon and striatum and correlation with age The raw integrated density (IntDen) (area $\times$ mean intensity) of the MHC-II signal was measured using ImageJ. The MHC-II expression between patient and control individuals was analyzed using 
Mann-Whitney $t$ test in Graphpad. To analyze whether there was a correlation between the expression of MHC-II in mesencephalon versus striatum, linear regression was performed on the average IntDen of all the 40 images from each individual. To analyze whether there was a correlation between the expression of MHC-II and the age of the individuals in the PD group and in the control group, linear regression was performed on the average IntDen of the MHC II staining versus age.

Measurement of the $\mathrm{GLAST}^{+} / \mathrm{MHC}-\mathrm{II}^{+}, \mathrm{GFAP}^{+}$/ MHC- $\mathrm{II}^{+}$, and $\mathrm{Iba1}^{+} / \mathrm{MHC}-\mathrm{II}^{+}$area $\mathrm{The} \mathrm{MHC}-\mathrm{II}^{+}$and $\mathrm{GLAST}^{+}$areas, the MHC-II ${ }^{+}$and $\mathrm{GFAP}^{+}$areas, and the

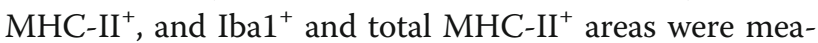
sured in all images. Based on co-localization of MHC-II and GLAST, GFAP and Iba1 positive staining respectively, the percentage of $\mathrm{GLAST}^{+} / \mathrm{MHC}^{-\mathrm{II}^{+}}, \mathrm{GFAP}^{+}$/

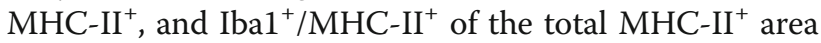
was calculated. The comparison between the patient and control group was performed using Student $t$ test.

Correlation between MHC-II staining and p-ser 129 aSYN staining in mesencephalon Mesencephalon sections were stained for $\mathrm{p}$-ser $129 \alpha \mathrm{SYN}(\mathrm{p}-\alpha \mathrm{SYN})$, and forty images were taken from each patient. Using Image J, IntDen for $\mathrm{p}-\alpha \mathrm{SYN}$ was measured. Non-linear regression with exponential model was performed on the $\mathrm{MHC}-\mathrm{II}$ and the $\mathrm{p}-\alpha \mathrm{SYN}$ IntDen.

\section{Cell culture experiments}

All data presented are based on analyses of three independent cell culture experiments.

\section{Immunocytochemistry}

The human astrocytes were stained with specific antibodies for LAMP-1, MHC-II, MHC-I, and PDL-1. From each experiment, 12 images were captured for each marker.

\section{Flow cytometry}

The flow cytometry data was analyzed using ANOVA with Bonferroni correction in GraphPad Prism.

\section{Results}

The majority of the MHC-II in the PD brain overlaps with astrocytic markers

We first sought to investigate if there was a correlation between PD pathology and the expression of MHC-II. The presence of Lewy body pathology in PD cases and the absence of pathology in the control cases were confirmed by staining brain sections with $\alpha \mathrm{SYN}$ and p$\alpha S Y N$ antibodies (Fig. 1a). In order to investigate if the levels of MHC-II are different between PD brains and control brains, we performed immunostainings for MHC-II and $p-\alpha S Y N$. Quantifications of MHC-II IntDen (area $\times$ mean intensity) in mesencephalon demonstrated a significant increase of MHC-II expression in PD patients compared to healthy controls (Fig. 1b). Interestingly, we could observe a clear correlation between MHC-II expression and the presence of $\mathrm{p}-\alpha \mathrm{SYN}$ in the PD brains (Fig. 1c). Subsequently, we performed immunostainings for MHC-II in striatum to investigate if there was a correlation between MHC-II expression in different regions of the nigrostriatal pathway, which is heavily affected by $\alpha \mathrm{SYN}$ pathology in PD. Indeed, we found a correlation of MHC-II expression between mesencephalon and striatum in the PD brains, but not in the control brains (Fig. 1d, e). To clarify whether the age of the patients had any impact on the MHC-II expression, we performed linear regression on the MHC-II and the age in the PD group and in the control group. Our analysis demonstrates that there is no correlation between age and the expression of MHC-II in the material included in this study (61-84 years of age) (Additional file $1 \mathrm{a}$ and $\mathrm{b}$ ).

Moreover, the immunohistochemical staining showed that MHC-II co-localized with the astrocytic markers GLAST (Fig. 1f) and GFAP (Fig. 1g), as well as with the microglial marker Ibal (Fig. 1h) in both PD and control brain sections, demonstrating that both microglia and astrocytes express MHC-II. To analyze the frequency of MHC-II expression in the various cell types, the respective overlaps of MHC-II with GLAST, GFAP, and Iba1 were quantified. In both PD and control brains, one third (35 and $31 \%$, respectively) of the MHC-II area overlapped with $\mathrm{GLAST}^{+}$astrocytes (Fig. 1i). There was no significant difference in the total $\mathrm{GLAST}^{+}$area between controls and patients, confirming GLAST expression by both nonreactive and reactive astrocytes (Additional file 2a). Moreover, 15\% of the MHC-II area overlapped with reactive $\mathrm{GFAP}^{+}$astrocytes in PD brains and $10 \%$ in control brains (Fig. 1j). Importantly, GFAP stains the cytoskeleton of the astrocyte, which only constitutes $15-20 \%$ of the cell [24]. Hence, the whole astrocyte is much bigger than the GFAP staining, and the overlap with MHC-II and GFAP will only reflect a proportion of the MHC-II expressing reactive astrocytes. In contrast to GLAST, there was an increase in $\mathrm{GFAP}^{+}$area in PD patients compared to controls (Additional file 2 a). Double staining of GLAST and GFAP (Additional file 2b) show that the two markers overlap very little, which was expected since they label different parts of the astrocyte. While GFAP is a cytoskeleton protein, GLAST is expressed in the plasma membrane of the cells. Moreover, the expression levels of GFAP and GLAST vary between different astrocytic subclasses. Hence, the combined result from the MHC-II/GLAST and MHC-II/GFAP staining 


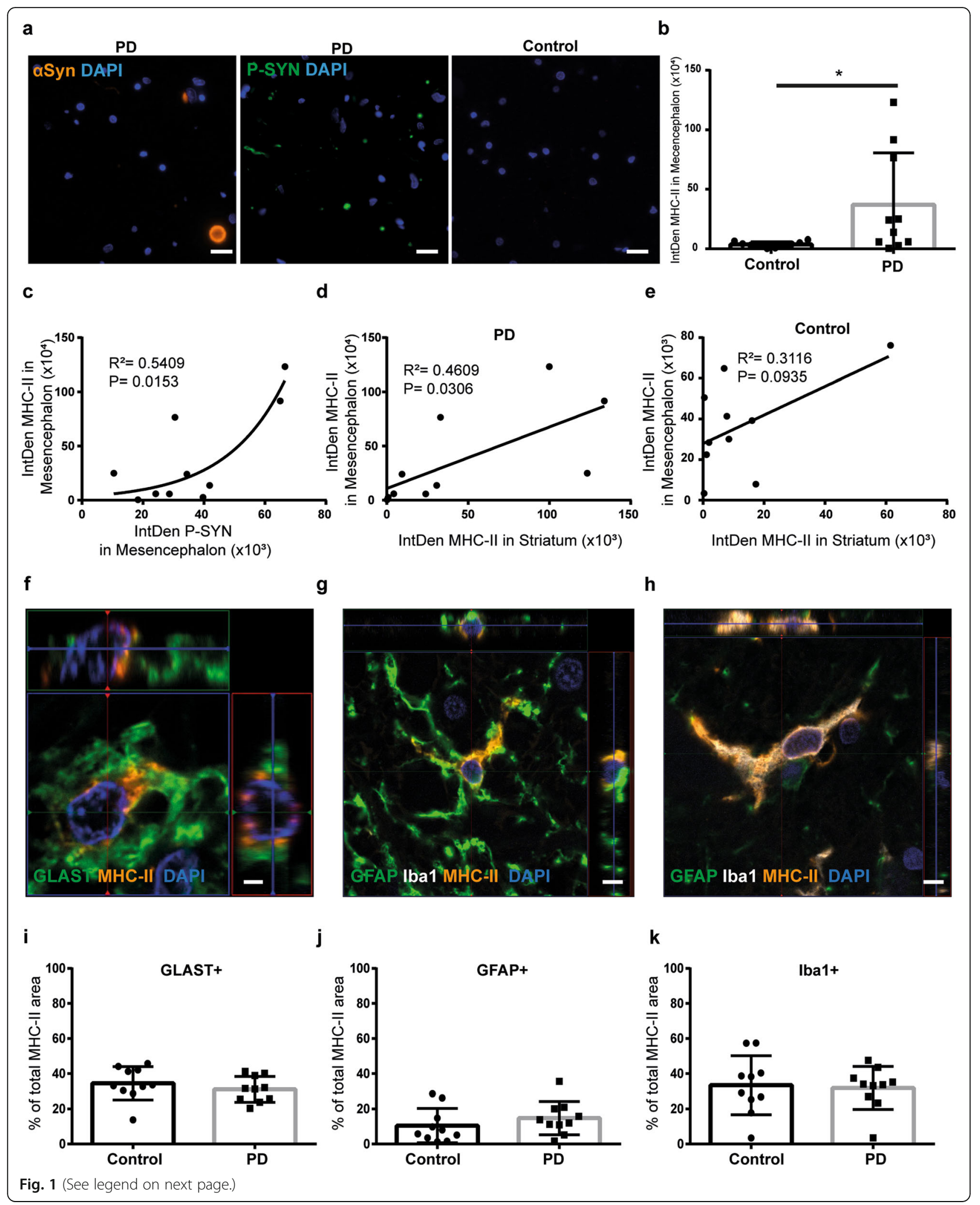


(See figure on previous page.)

Fig. 1 Human astrocytes express MHC-II in brain tissue from PD patients and healthy controls. The aSYN pathology was confirmed in the PD cases by immunostaining of aSYN and phosphorylated aSYN (p-aSYN) (a). The PD brains express higher levels of MHC-II compared to control brains (b). MHC- $-\|$ levels correlate with the expression of p-aSYN in PD brains (c). There is a correlation between the MHC-II levels in the mesencephalon and striatum in the PD brains, but not in the control brains (d, e). Astrocytes labeled with GLAST (f) or GFAP (g) are expressing high levels of MHC-ll, as well as Iba1-labeled microglia (h). Quantifications of the immunostainings revealed that 31\% of the MHC-II area overlapped with the astrocyte marker GLAST (i), 15\% overlapped with the reactive astrocyte marker GFAP (j), and $32 \%$ overlapped with the microglia marker lba1 in the PD brain (k). A similar overlap between MHC-II and GLAST, GFAP, and Iba1 (35\%, 10\%, and 33\%, respectively) was revealed from the analysis of the control brains $(\mathbf{j}-\mathbf{k})$. Scale bars: $\mathbf{a}=20 \mu \mathrm{m} ; \mathbf{f}=$ $2 \mu \mathrm{m} ; \mathbf{g}, \mathbf{h}=5 \mu \mathrm{m}$

show that almost $50 \%$ of the MHC-II overlapped with either of the astrocytic markers. Both in PD and control brains, approximately one third (33\% and 32\%, respectively) of the MHC-II area overlapped with Iba1 (Fig. 1k). Similar to GFAP, the total Ibal area was increased in PD patients, compared to controls (Additional file 2a). The remaining $\mathrm{MHC}$ positive cells (approximately 20\%) may reflect $\mathrm{MHC}-\mathrm{II}^{+}$infiltrating immune cells and/or GLAST-GFAP-MHC-II+ astrocytes. Hence, although the expression of MHC II is increased in the PD brain, the overlap with astrocytic markers and microglial markers is not significantly different. The most likely explanation is that the same cells express MHCII in the healthy brain and in the PD brain, but that their expression level is higher in the PD brain.

\section{Exposure to aSYN-F does not result in surface expression of co-stimulatory molecules in human microglia}

Due to their myeloid origin, microglia cells have been addressed as the primary antigen-presenting cells in the brain. To investigate antigen presentation capacities of microglia in PD, adult human microglia were exposed to sonicated $\alpha S Y N$ preformed fibrils $(\alpha S Y N$ F) (Fig. 2a). The $\beta$-sheet structure of the $\alpha \mathrm{SYN}-\mathrm{F}$ was assessed with ThT assay (Additional file 3a), and TEM was performed to compare the $\alpha \mathrm{SYN}-\mathrm{F}$ before and after the sonication (Additional file 3b-c). Immunostaining for the lysosomal marker CD68, a phagocytic marker specific for microglial cells, illustrated intracellular accumulation of $\alpha \mathrm{SYN} 7 \mathrm{~d}$ after exposure (Fig. 2b). Flow cytometry analysis showed upregulation of surface expression of MHC-I and MHC-II and the co-stimulatory molecules CD80, CD86, and CD40 (Fig. $2 \mathrm{c}-\mathrm{g}$ ) upon treatment with IFNy, verifying that the microglia were healthy and responded normally to surrounding inflammatory signals. However, exposure of the microglia to $\alpha S Y N-F$ did not result in increased surface expression of MHC-I and MHC-II or any of the co-stimulatory molecules important for $\mathrm{T}$ cell activation (Fig. 2c-g). These results indicate that microglia cells are not capable of activating $\mathrm{T}$ cells following exposure to $\alpha \mathrm{SYN}-\mathrm{F}$.

\section{Human astrocytes express co-stimulatory molecules following exposure to aSYN-F}

Based on our findings that approximately half of the MHCII-expressing cells in the PD brain are astrocytes, we next investigated whether astrocytes can act as antigenpresenting cells upon $\alpha S Y N-F$ exposure. Subsequently, human astrocytes expressing the astrocytic markers GFAP, GLAST, ALDH1L1, vimentin, and S100 $\beta$ (Additional file 4) were exposed to $\alpha \mathrm{SYN}-\mathrm{F}$ for 7 days (Fig. 3a). Flow cytometry analysis revealed cell surface expression of MHC-II, MHC-I, and PDL-1 (Fig. 3b-d) upon stimulation with IFN $\gamma$. Interestingly, cell surface expression of the co-stimulatory molecules CD80, CD86, and CD40 (Fig. 3e-g) were only detected following exposure to sonicated $\alpha S Y N-F$. These results demonstrate that $\alpha S Y N-F$ stimulate the astrocytes to express the co-stimulatory molecules necessary for professional APCs to activate $\mathrm{CD} 4^{+} \mathrm{T}$ cells.

\section{Intracellular deposits of aSYN in human astrocytes are surrounded by MHC-II}

Professional APCs have the ability to present antigens with both MHC-II and MHC-I molecules, enabling them to activate both $\mathrm{CD}^{+}$and $\mathrm{CD}^{+} \mathrm{T}$ cells. In order to investigate whether $\alpha \mathrm{SYN}-\mathrm{F}$ and $\mathrm{MHC}-\mathrm{I} / \mathrm{II}$ are in close proximity in the human astrocytes, we performed immunocytochemistry. In line with our recently published data [15], the human astrocytes accumulated large amounts of aggregated $\alpha S Y N$, while monomeric $\alpha S Y N$ was rapidly degraded by the cells (Fig. 4a, b). In accordance with the flow cytometry data, the number of cells expressing MHC-II and MHC-I in control cultures and $\alpha \mathrm{SYN}$-F-exposed cultures was similar. Stimulation with IFNY increased the number of MHC-II positive cells as well as the expression of MHC-I (Fig. 4a, b) and PDL-1 (Additional file 5). Interestingly, in the $\alpha S Y N$ and $\alpha \mathrm{SYN}+\mathrm{IFN} \gamma$-treated astrocyte cultures, the majority of aSYN aggregates were surrounded by MHC-II . The localization of MHC-II, forming a capsule around the deposited $\alpha \mathrm{SYN}$, was confirmed with confocal microscopy (Fig. 4c, c'). These data together with the flow cytometry results strongly suggest an involvement of the MHC-II pathway in astrocytes when exposed to $\alpha \mathrm{SYN}-\mathrm{F}$. Furthermore, immunostainings revealed MHC-I expression in the 


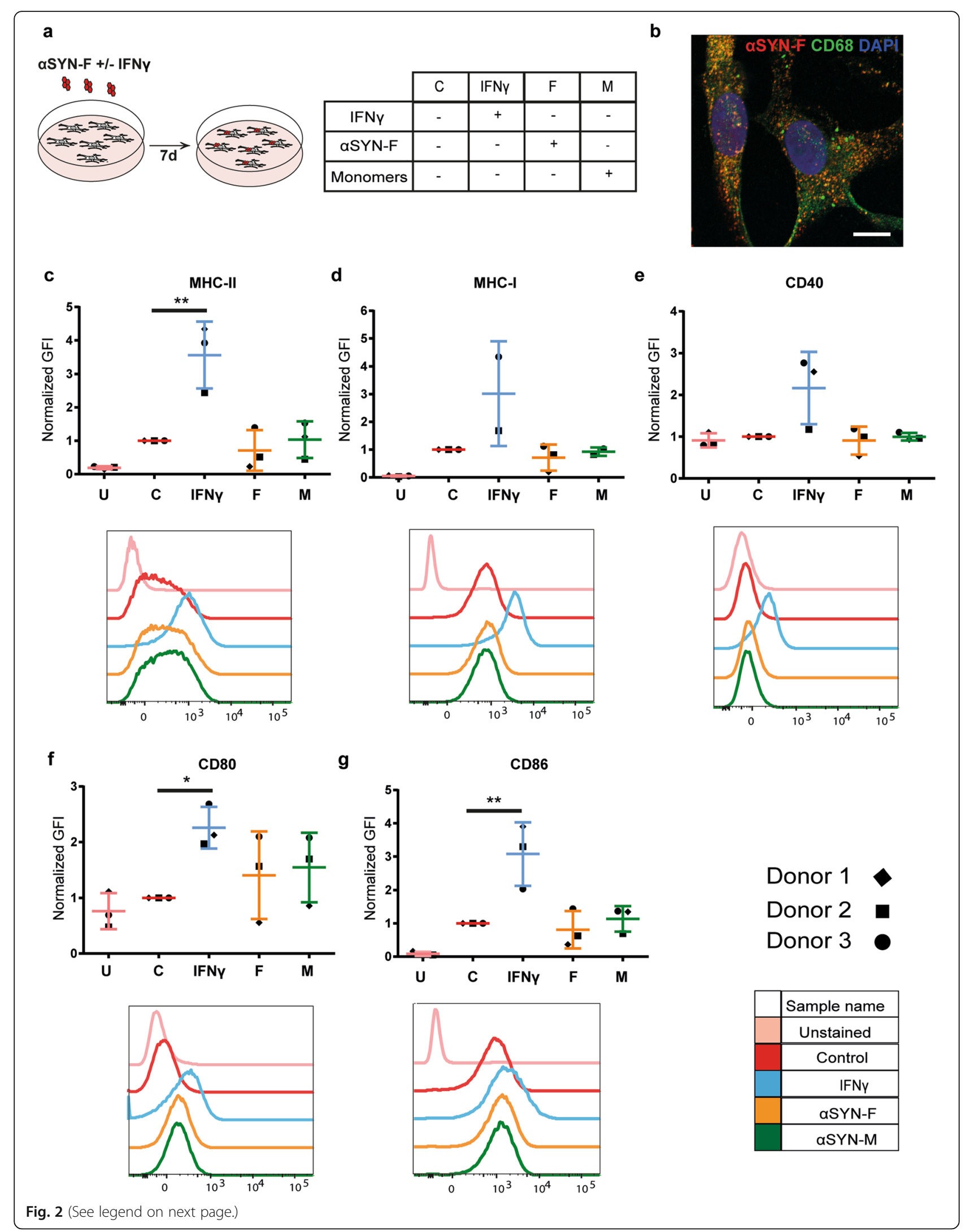


(See figure on previous page.)

Fig. 2 Human microglia do not express markers required for activation of $C D 4^{+} T$ cells, following aSYN-F treatment. Schematic illustration of study setup and the different treatment groups (a). Human microglia accumulate aSYN that partially co-localize with the lysosomal marker CD68 (b). Flow cytometry analysis revealed that microglia cells upregulate MHC-II (c) and MHC-I (d) upon IFNy treatment,which are involved in activation of T cells. However, when exposed to aSYN-F, the microglia did not express co-stimulatory markers CD40 (e), CD80 (f), and CD86 (g) that are all necessary for activating $C D 4^{+} T$ cells. $U$, unstained samples; GFI, geometric fluorescence intensity

proximity of the intracellular $\alpha \mathrm{SYN}$ deposits and partial encapsulation of $\alpha S Y N$ was also observed for MHC-I, using confocal microscopy (Fig. 4d, d'). Since both MHC-I and II co-localize with $\alpha \mathrm{SYN}$ aggregates, astrocytes might process $\alpha \mathrm{SYN}$ as an antigen through both pathways, which further proposes their role as antigen presenting-cells.

\section{Intracellular aSYN and MHC-II are situated in LAMP-1 positive vesicles}

MHC-II molecules encounter their antigen in late endosomal, lysosomal vesicles and are then transported to the cell surface. To find out if the $\alpha S Y N$ deposits that are surrounded by MHC-II are within the same cellular compartment, immunocytochemistry with the lysosomal marker LAMP-1 was performed. The immunostainings revealed that the ingested $\alpha S Y N-F$ enter the endo-lysosomal pathway (Fig. 5a, b). The localization of the $\alpha S Y N$ deposits within LAMP-1 positive vesicles was confirmed by confocal microscopy (Fig. 5c). To find out whether the intracellular MHC-II is also surrounded by LAMP-1 positive vesicles, human astrocytes treated with unlabeled $\alpha S Y N-F$ were stained with MHC-II and LAMP-1. Confocal microscopy demonstrated that LAMP-1 positive vesicles indeed surrounded the MCH-II molecules in the $\alpha S Y N-F$-treated astrocytes (Fig. $5 d$, d').

\section{Deposits of aSYN and MHC-II are transferred between astrocytes via tunneling nanotubes}

Several studies have suggested that aggregated $\alpha S Y N$ are transferred via tunneling nanotubes (TNTs) between astrocytes and between astrocyte and neurons [15, 25]. We wanted to explore whether MHC-II molecules also can spread between the human astrocytes and, if so, whether $\mathrm{MHC}-\mathrm{II}$ and $\alpha \mathrm{SYN}$ could be transported together from one cell to another. Immunostainings and confocal imaging showed that the MHC-II molecules were indeed transferred between the human astrocytes (Fig. 6a), suggesting that inflammatory molecules could be propagated from one astrocyte to another. Cell-to-cell transportation was detected in both control and $\alpha S Y N-F$ exposed cultures. Additionally, confocal microscopy showed that the $\alpha \mathrm{SYN}$ deposits surrounded by MHC-II also spread between the cells (Fig. 6b). These data suggest that the inflammation, as a part of the pathology, can spread from one astrocyte to another.
MHC-II expressing astrocytes are situated in close contact with $\mathrm{CD}^{+} \mathrm{T}$ cells

To examine whether astrocytes and $\mathrm{CD}^{+} \mathrm{T}$ cells are in direct contact with each other, human mesencephalon sections from PD post mortem brains were stained with specific antibodies to MHC-II, GFAP, and CD4. Infiltration of $\mathrm{CD}^{+} \mathrm{T}$ cells was observed in all the post mortem brain sections. Both perivascular and infiltrated $\mathrm{T}$ cells were demonstrated to be in contact with and closely surrounded by MHC-II expressing astrocytes (Fig. $7 \mathrm{a}-\mathrm{c}$ ). Taken together, our data demonstrate that the astrocytes are capable of expressing all factors that are required for $\mathrm{CD}_{4}^{+} \mathrm{T}$-cell activation, suggesting their involvement in $\mathrm{T}$-cell activation during PD progression.

\section{Discussion}

Accumulating evidence indicates that astrocytes can play a central role during PD progression. Reactive astrocytes are known to ingest large amounts of aggregated $\alpha S Y N$ that are intracellularly stored, rather than degraded [8$14,26]$. We have previously shown that accumulation of aggregated $\alpha \mathrm{SYN}$ in human astrocytes disrupts their lysosomal machinery and induces cell-to-cell transfer of $\alpha S Y N$ via tunneling nanotubes [15]. Slow degradation of engulfed antigens is an important feature of professional APCs, enabling them to present antigens to $\mathrm{T}$ helper cells. Studies in multiple sclerosis and experimental autoimmune encephalomyelitis suggest that astrocytes are capable of activating both Th1 and Th17 T cells [27, 28], highlighting their central role in the inflammation process. However, no study has yet investigated the interplay between astrocytes and T cells in PD.

Here, we report for the first time that $\alpha \mathrm{SYN}$-accumulating astrocytes have the capacity to perform as professional APCs, indicating that they are important for the $\mathrm{T}$ cell response in PD. When exposed to fibrillary $\alpha \mathrm{SYN}$, human astrocytes express the co-stimulatory molecules CD80, CD86, and $\mathrm{CD} 40$ that are crucial for activation of $\mathrm{CD}^{+} \mathrm{T}$ helper cells, as well as MHC class I and II. Hence, the $\alpha S Y N$ accumulating astrocytes have all the molecules necessary for activating the infiltrating $\mathrm{T}$ cells. To confirm that astrocytes are in contact with $\mathrm{CD}^{+} \mathrm{T}$ cells in the PD brain, we performed immunostainings of post mortem tissues from PD patients. We detected CD4. ${ }^{+} \mathrm{T}$ cells within, as well as outside of the perivasculature. Interestingly, both the $\mathrm{T}$ cells situated in the vessel wall and in the brain parenchyma were found to be in very close proximity with $\mathrm{MHC}-\mathrm{II}^{+}$astrocytes. Since 
a

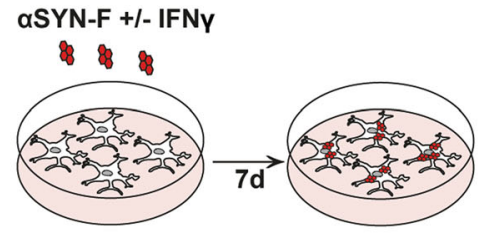

b
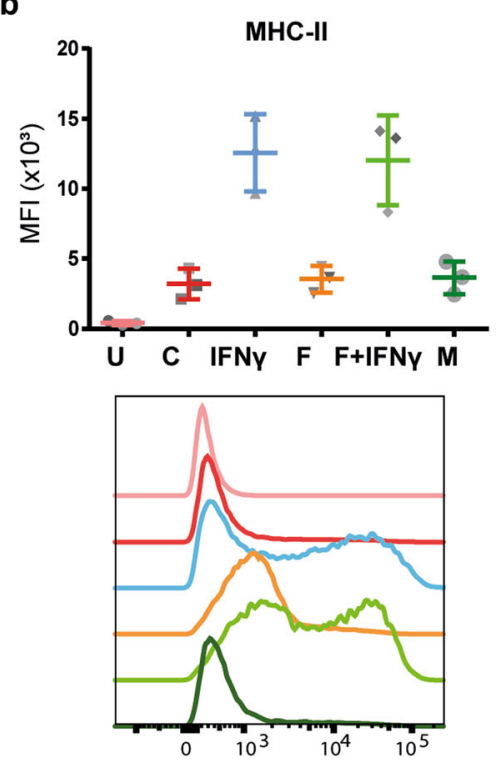

e
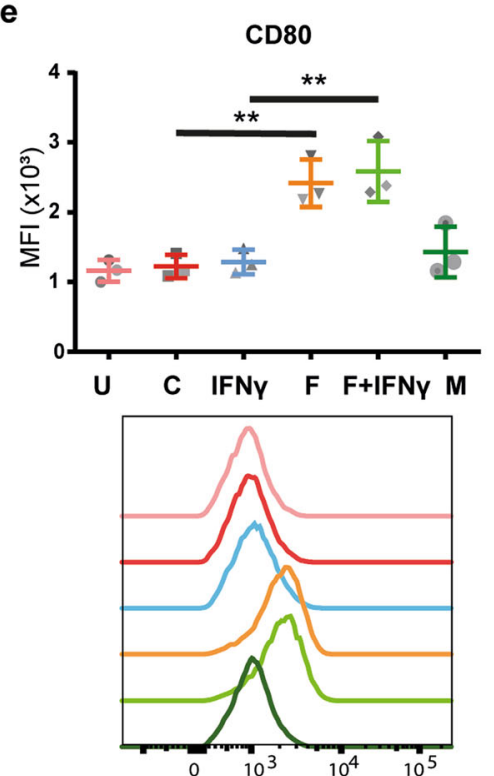

c
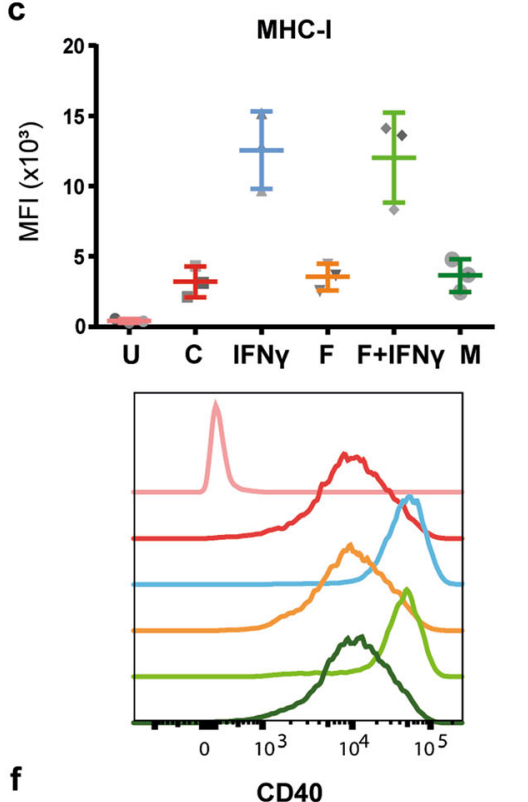

f
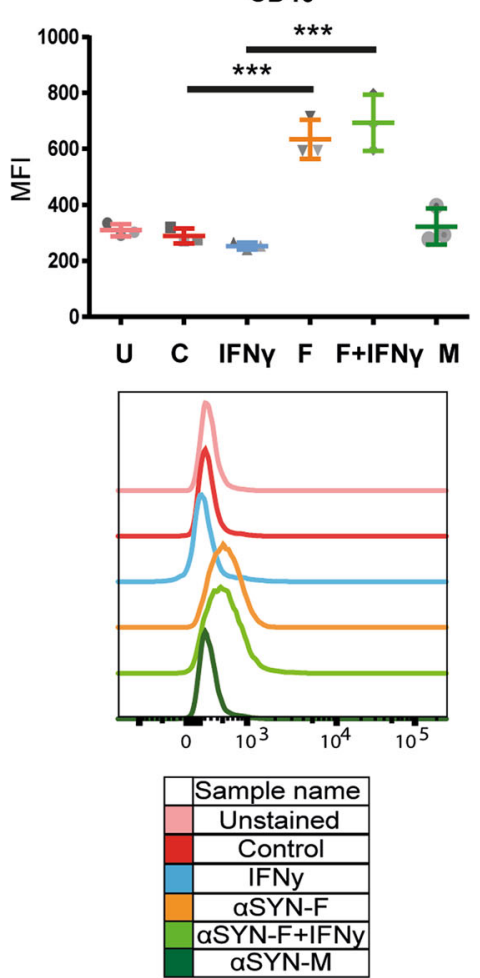
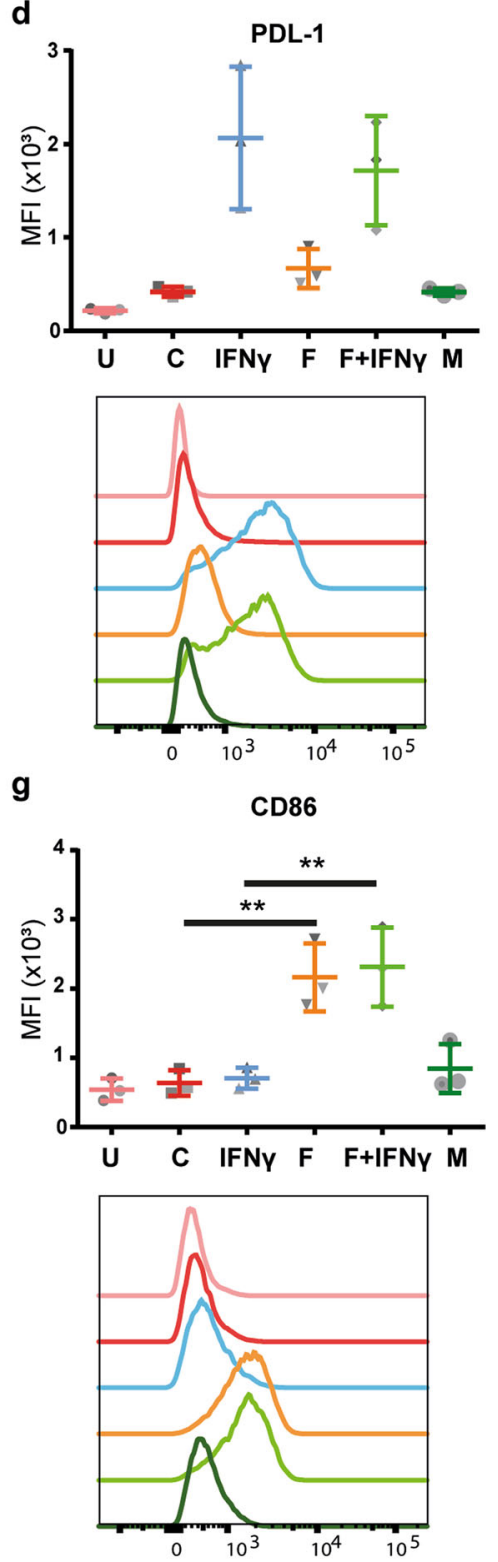

Fig. 3 (See legend on next page.) 
(See figure on previous page.)

Fig. 3 Human astrocytes express all markers required for activation of $C D 4^{+} T$ cells following aSYN-F treatment. Schematic illustration of study setup and the different treatment groups (a). Flow cytometry analysis illustrated that astrocytes upregulate MHC-II (b), MHC-I (c), and PDL1 (d) upon IFNy treatment, which are involved in activation (MHC-II and MHC-I) and inhibition (PDL1) of T cells. Notably, when exposed to aSYN-F, the astrocytes express all co-stimulatory markers $\operatorname{CD} 40(\mathbf{e}), \mathrm{CD} 80(\mathbf{f})$, and CD86 $(\mathbf{g})$ that are crucial for activating $\mathrm{CD}^{+} \mathrm{T}$ cells. U, unstained samples; MFI, mean fluorescence intensity

astrocytic end feet are lining the blood vessels, astrocytes could activate the $\mathrm{T}$ cells before or during their recruitment to the brain parenchyma.

Due to their myeloid origin, microglia are often suggested to be the primary APC in the brain, irrespectively of disease condition. However, several studies indicate that microglia are often poor antigen presenters [19-21], indicating that other glial cell types may instead be important for T-cell activation. For example, a recent investigation suggests that MHC-II-expressing oligodendrocyte progenitor cells (OPCs) may play a role in T-cell activation in multiple sclerosis [29]. Notably, we show that human microglia, isolated from adult brain tissue, do not express the co-stimulatory molecules necessary for T-cell activation upon $\alpha \mathrm{SYN}-\mathrm{F}$ exposure. Hence, our data indicate that astrocytes could be highly responsible for T-cell activation in the PD brain. Whether the astrocyte/T cell interplay is beneficial or detrimental for the disease progression, however, remains to be investigated.

Different types of $\mathrm{T}$ cells can be defined by the combinations of cell surface markers they express and the cytokines they secrete. Cytotoxic $\mathrm{CD}^{+} \mathrm{T}$ cells secrete IFN $\gamma$ and are stimulated via the MHC-I pathway. The $\mathrm{CD} 4^{+} \mathrm{T}$ helper cells are divided into four subgroups: Th1, Th2, Th17, and regulatory $\mathrm{T}$ cells. These are activated through the MHC-II pathway and Th1/17 secrete IFNY upon stimulation, whereas Th2 secrete IL-4 [30]. Alteration in the levels of Th1 and Th17 has been observed in the blood of PD patients [31-33]. Secretion of IFNY by T cells stimulates expression of MHC-I, MHC-II, and the coinhibitory molecule PDL-1 which is important for inhibition of $\mathrm{T}$ cells. To confirm that cultured human astrocytes express MHC-II and PDL-1 (that are regulated by IFN $\gamma$ levels), the astrocytes were subjected to IFNy. Immunostainings and flow cytometry analysis confirmed an increase of both endogenous and surface MHC-I, MHC-II, and PDL-1 in the astrocyte culture in response to IFN $\gamma$. Our findings indicate that astrocytes may be involved in the regulation of $\mathrm{T}$ cell function in the brain as they express both stimulatory and inhibitory molecules.

Antigens possess independent binding sites for both MHC-I and II molecules/complexes [34]. In addition to aggregation, $\alpha S Y N$ undergoes different posttranslational modifications during disease progression, including phosphorylation $[35,36]$. In a recent study, $\alpha \mathrm{SYN}$ was suggested to have two MHC-II binding sites, one of which contains the ser129 phosphorylation site [3]. Immunostainings of post mortem mesencephalon tissue demonstrated higher levels of MHC-II in PD patients, compared to controls. Interestingly, the burden of ser129-phosphorylated $\alpha \mathrm{SYN}$ in the mesencephalon of PD patients correlated with the MHC-II levels. Furthermore, we observed a correlation in MHC-II levels in striatum and mesencephalon in PD, but not in the controls. The nigrostriatal pathway, which includes mesencephalon and striatum, is heavily affected by $\alpha \mathrm{SYN}$ pathology, explaining the correlation of MHC-II levels between the two regions. Consistently, another study found that the total burden of $\alpha S Y N$ correlate with MHCII in PD brain [37]. Immunostaining for GLAST, GFAP, and Iba1 indicated co-localization of both astrocytes and microglia with MHC-II in the PD brain. Subsequently, quantifications of the MHC-II + GLAST ${ }^{+}$area revealed that $31 \%$ of total MHC-II, expressed in the mesencephalon sections, co-localized with the astrocytic marker, demonstrating that a high proportion of the MHC-II ${ }^{+}$cells are indeed astrocytes.

In addition, $15 \%$ of the MHC-II area co-localized with GFAP and 32\% co-localized with the microglia marker Iba1. The remaining MHC-II are most likely expressed by other cell types, such as macrophages situated in the blood vessels or by astrocytes that lack both GLAST and GFAP. Astrocytes are highly heterogeneous cells with different protein expression and different functions [38]. Interestingly, our staining shows that there is very little overlap between the GLAST and GFAP, indicating that the two markers identify different parts of the astrocytes and/or different astrocytic subclasses. Hence, in combination, our results show that almost $50 \%$ of the MHC-II is situated within astrocytes. It is also important to remember that GFAP only stains $15-20 \%$ of the astrocyte [24], which most likely results in a considerable underestimation of the MHC-II expressing $\mathrm{GFAP}^{+}$astrocytes. Due to the limited number of patients included in the study, additional investigation of human brain material is necessary to fully understand the role of astrocytes in antigen presentation and T-cell activation in the PD brain. However, we performed extensive investigations of cultured human cells, confirming the antigen presenting capacity of astrocytes.

Endogenous antigens are presented via the MHC-I pathway where the antigen is fragmented to 8-10 amino acids in the proteasomal degradation pathway. Binding between MHC-I and the antigen occurs in the ER, and the antigen-MHC-I complex is then transported to the 


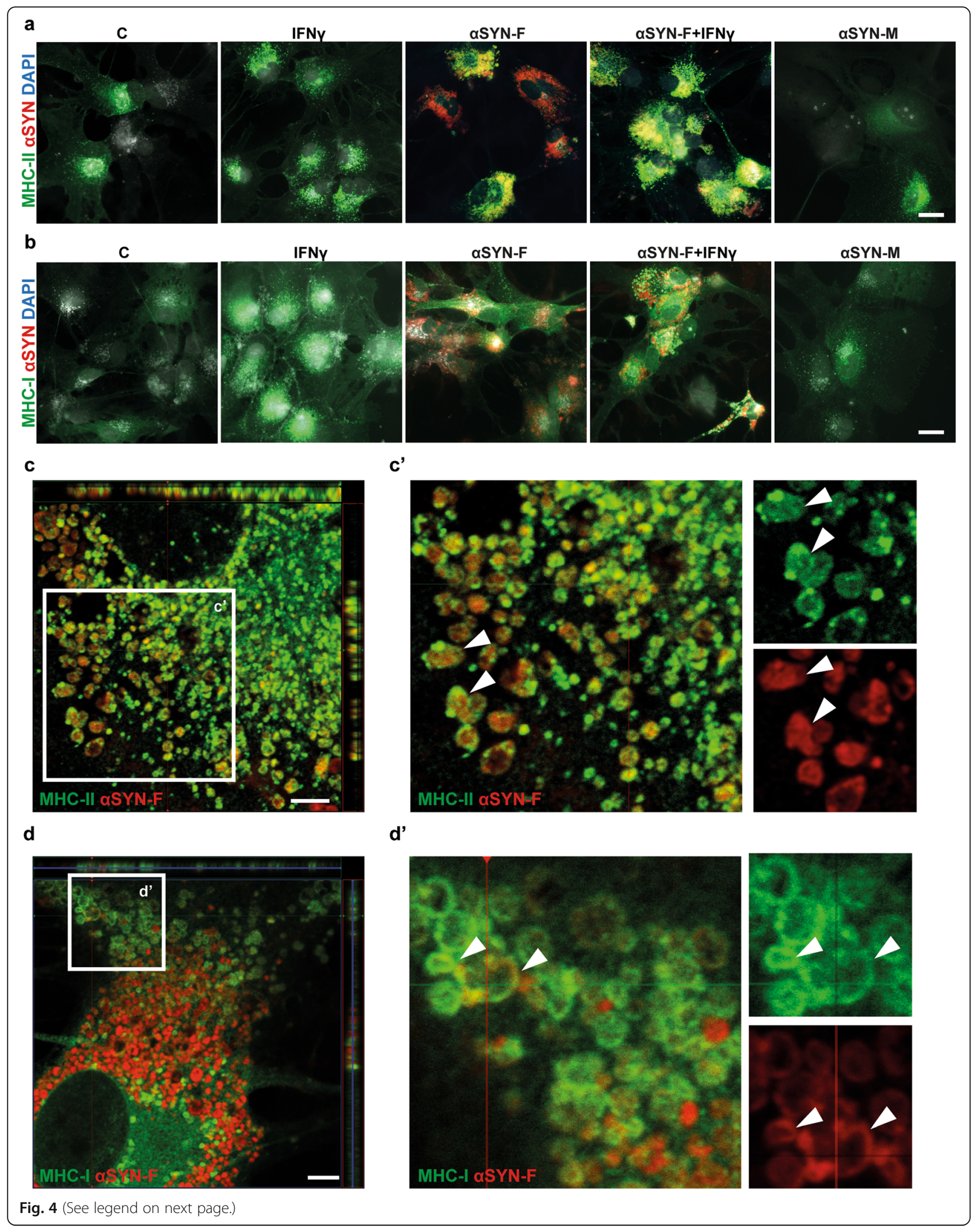


(See figure on previous page.)

Fig. 4 Intracellular deposits of aSYN in astrocytes are surrounded by MHC-II. Human astrocytes were exposed to aSYN-F for 7 days and stained for MHC-II and MHC-I. In the presence of IFNY, the astrocytes clearly upregulate MHC-II (a) and MHC-I (b). The MHC-II totally enclosed the aSYN inclusions, which was confirmed with confocal microscopy (c). Close-up of white rectangle in c is shown in c'. Immunostaining for MHC-I analyzed with confocal microscopy showed a partial encampsulation of the aSYN deposits by MHC-I (d). Close-up of white rectangle in $\mathbf{d}$ is shown in d'. Scale bars: $\mathbf{a}$ and $\mathbf{b}=20 \mu \mathrm{m}, \mathbf{c}$ and $\mathbf{d}=5 \mu \mathrm{m}$
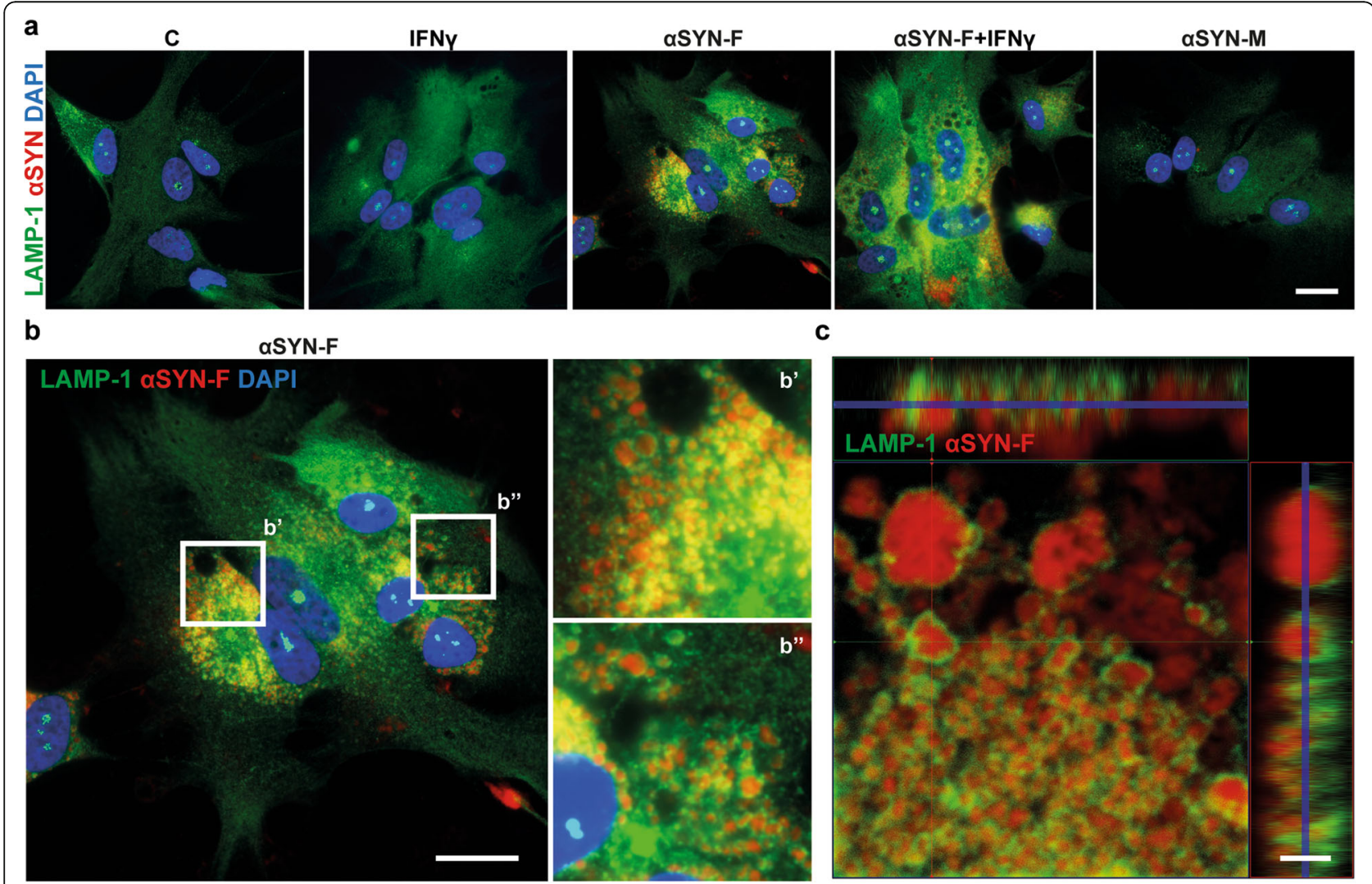

d

d'
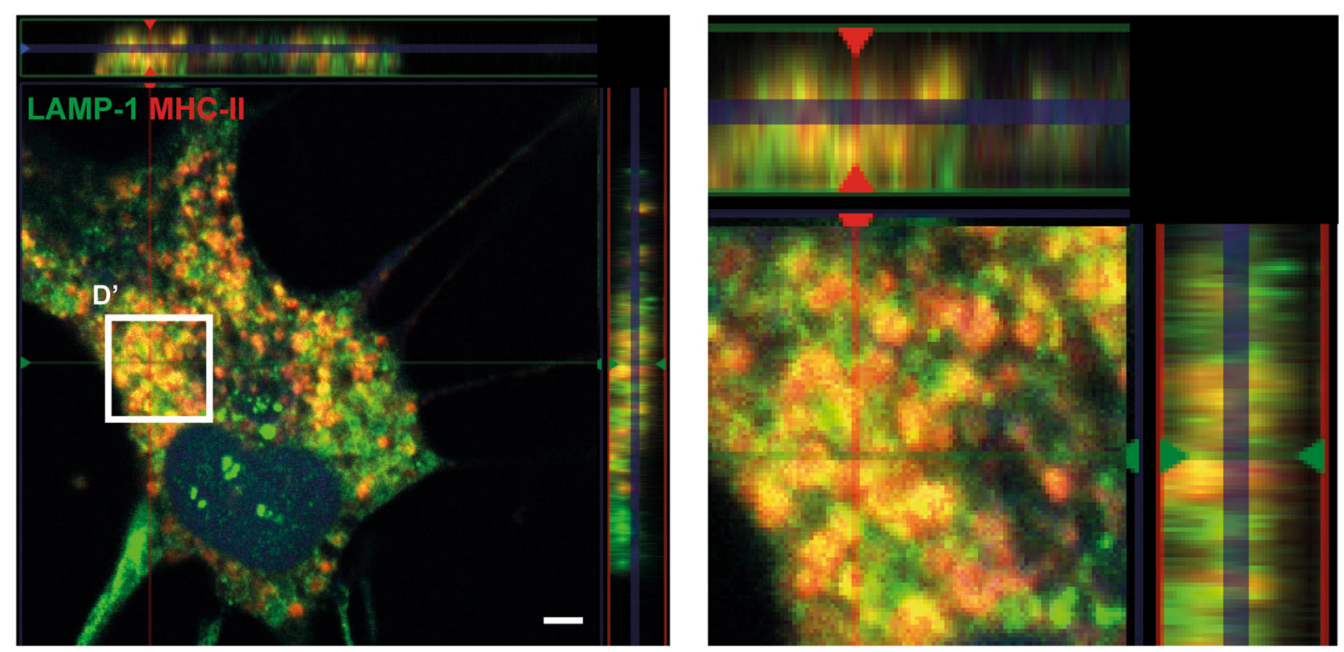

Fig. $5 \mathrm{MHC}-\|$ and $\mathrm{aSYN}$ are located in LAMP-1 positive vesicles. Immunostainings showed that the LAMP-1 expression pattern was altered in aSYN-F exposed astrocytes, but not in astrocytes exposed to aSYN-M or IFNY only (a). The aSYN deposits in aSYN-F exposed astrocytes are clearly localized within LAMP-1 positive vesicles (b). Close-up of white rectangles in b are shown in b' and b". Confocal analysis confirmed the localization of aSYN within the Iysosomal compartments (c). Stainings for MHC-II and LAMP-1 in astrocytes, exposed to unlabeled aSYN-F, confirmed that also MHC-II is located in the LAMP-1 positive vesicles (d).Close-up of the white rectangle in $\mathbf{d}$ is shown in $\mathrm{d}^{\prime}$. Scale bars: $\mathbf{a}, \mathbf{b}=20 \mu \mathrm{m} ; \mathbf{c}=2 \mu \mathrm{m}, \mathbf{d}=5 \mu \mathrm{m}$ 


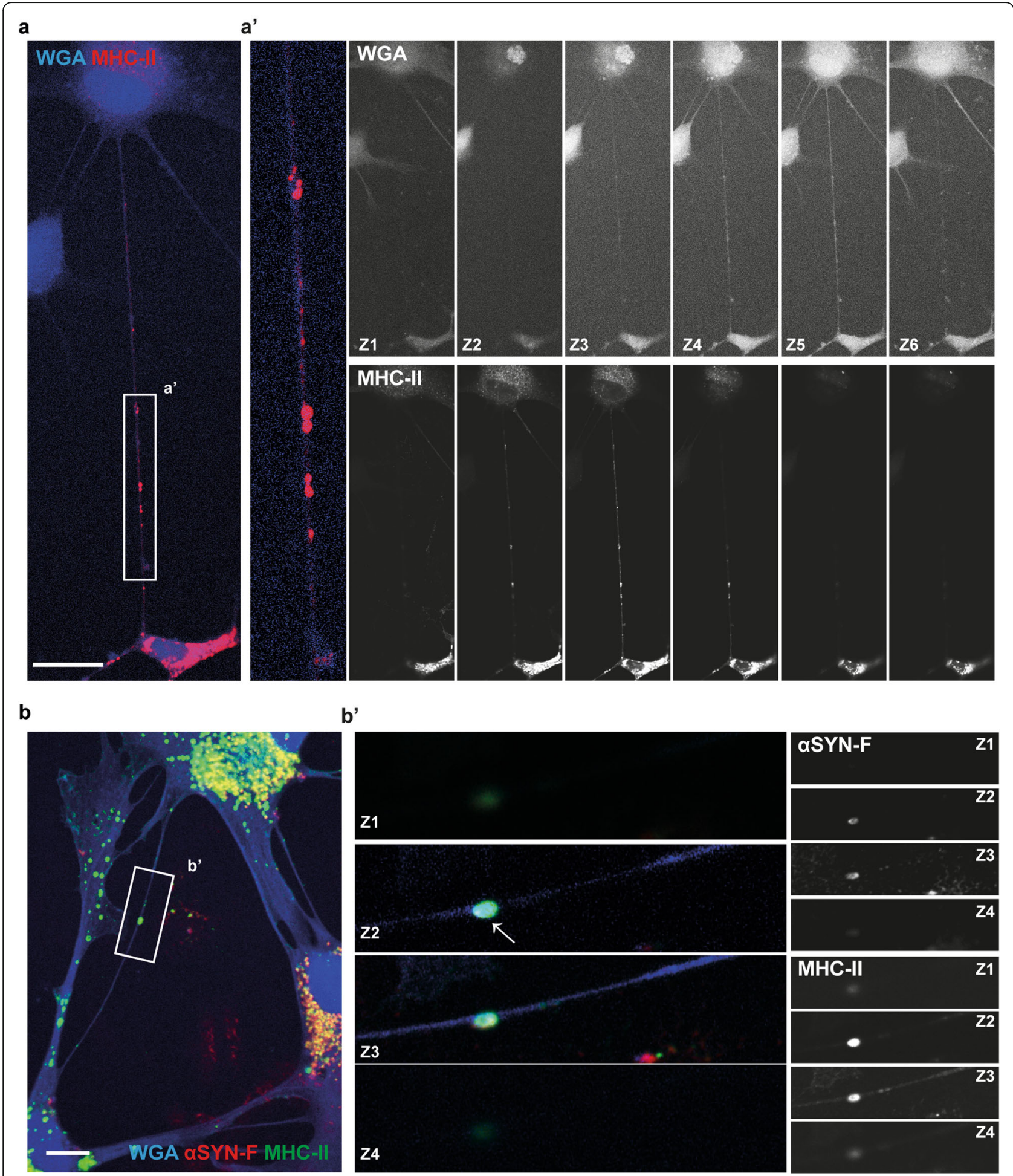

Fig. 6 Aggregated ASYN and MHC-II are transported between astrocytes via tunneling nanotubes. Immunostainings and confocal imaging demonstrated transfer of MHC-II between the astrocytes via WGA-labeled tunneling nanotubes (a). A close-up of the tunneling nanotube region (white rectangle) is shown in a'. The various z-planes (z1-z6) for the WGA-staining and MHC-II-staining are shown separately in black and white. Aggregates of aSYN and MHC-II could be detected in tunneling nanotubes connecting two astrocytes (b). A close-up of the tunneling nanotube region (white rectangle) is shown in b'. The various z-planes (z1-z4) for the aSYN and MHC-Il-staining are shown separately in black and white. Scale bars: $(\mathbf{a})=20 \mu \mathrm{m}$ and $(\mathbf{b})=10 \mu \mathrm{m}$ 

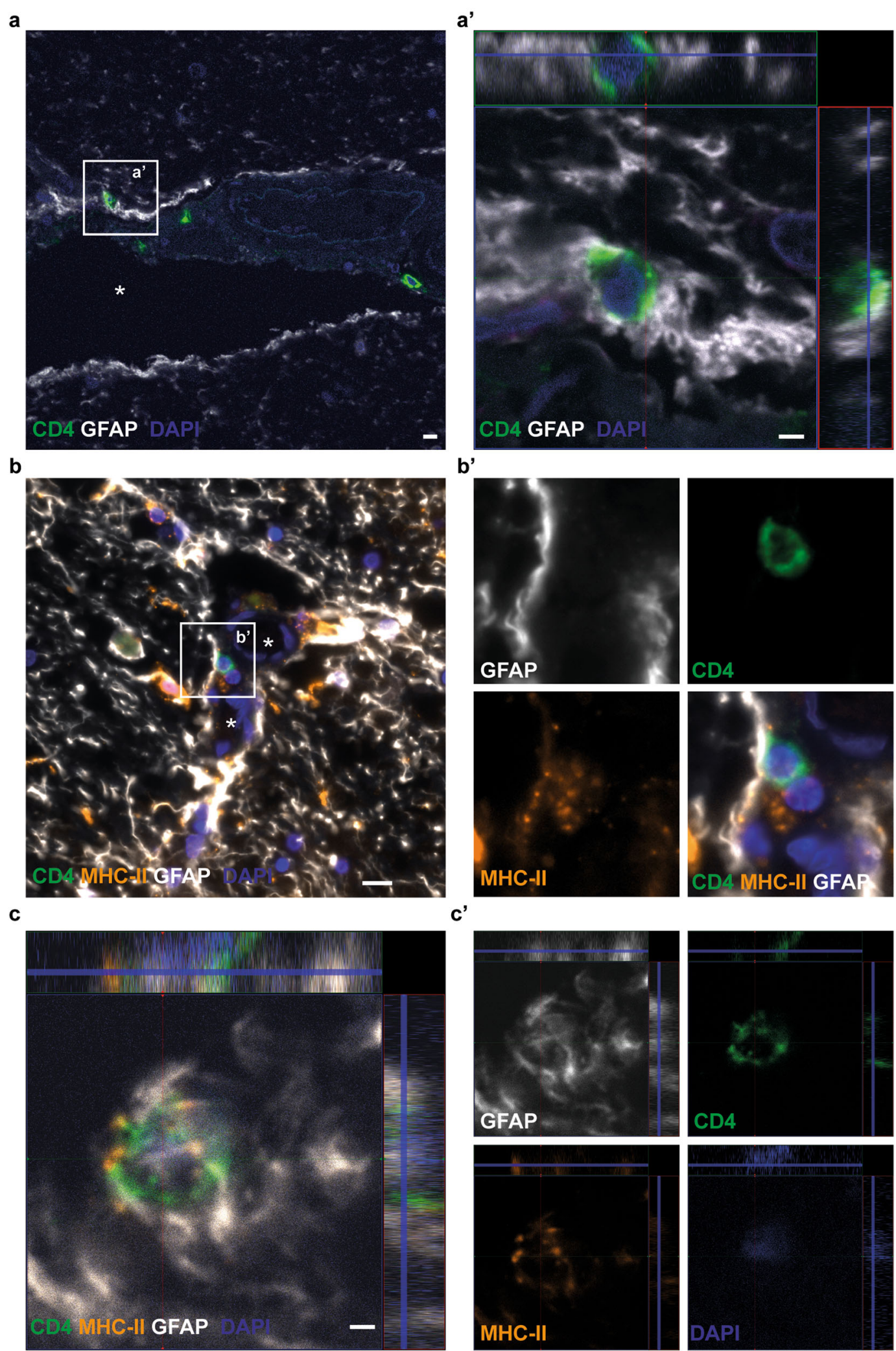

Fig. 7 (See legend on next page.) 
(See figure on previous page.)

Fig. $7 \mathrm{MHC}-\|$ expressing astrocytes are situated in close contact with CD4 ${ }^{+} \mathrm{T}$ cells in the human brain. Double immunostainings of GFAP and CD4 indicated close contact between perivascular $\mathrm{CD}^{+} \mathrm{T}$ cells and $\mathrm{GFAP}^{+}$astrocytes in the vessel wall (a). A close-up confocal image of the white rectangle is shown in $a^{\prime}$. Triple immunostainings with specific antibodies to GFAP, CD4, and MHC-II verified that there is an interaction between CD4 ${ }^{+}$ $T$ cells and MHC-II expressing astrocytes in the blood vessel wall (b). Close-up images of the separate channels are shown in $b^{\prime}$. Infiltrated CD4 ${ }^{+} \mathrm{T}$ cells in the parenchyma were also found to be encapsulated by MHC-II expressing astrocytes (c). The separate channels of the confocal image are shown to the right in $\mathbf{c}^{\prime}$. The blood vessels in (a) and (b) are indicated with white stars. Scale bars: (a and $\left.\mathbf{c}\right)=2 \mu \mathrm{m},(\mathbf{b})=20 \mu \mathrm{m}$

cell surface to interact with $\mathrm{CD}^{+} \mathrm{T}$ cells. Exogenous antigens that are ingested through endocytosis enter the endo-lysosomal pathway and are fragmented to 12-24 amino acids. These fragments are then presented to MHC-II, which is transported from the Golgi apparatus to the late endosomes where they bind to each other. The antigen-MHC-II complex is then transported to the cell surface, where it is presented to the $\mathrm{CD} 4^{+} \mathrm{T}$ helper cells [17]. Here, we show that the ingested $\alpha \mathrm{SYN}$ fibrils are surrounded by MHC-II in LAMP-1 positive vesicles, suggesting that $\alpha \mathrm{SYN}$ encounters MHC-II in the endolysosomes in astrocytes. Additionally, partial colocalization with MHC-I and $\alpha S Y N$ could be observed, suggesting that the ingested $\alpha \mathrm{SYN}-\mathrm{F}$ could be released into the cytosolic compartment and enter the proteasomal pathway. Co-localization of $\alpha S Y N$ aggregates by both MHC-I and II indicates that the astrocytes are capable of cross-presenting $\alpha S Y N$ as an antigen. By sending parts of the antigen to the MHC-I pathway, professional APCs can present via both MHC-I and II molecules resulting in activation of both $\mathrm{CD}^{+}$and $\mathrm{CD} 4^{+} \mathrm{T}$ cells. These data indicate that $\alpha \mathrm{SYN}$ fibrils, once ingested by the astrocytes, act as an antigen for the MHC-II pathway, but to some degree also for the MHC-I pathway.

We have previously shown that $\alpha \mathrm{SYN}$ accumulation induce the formation of tunneling nanotubes between astrocytes [15]. The stressed astrocytes use the nanotubes to transfer $\alpha \mathrm{SYN}$ to neighboring cells. Professional

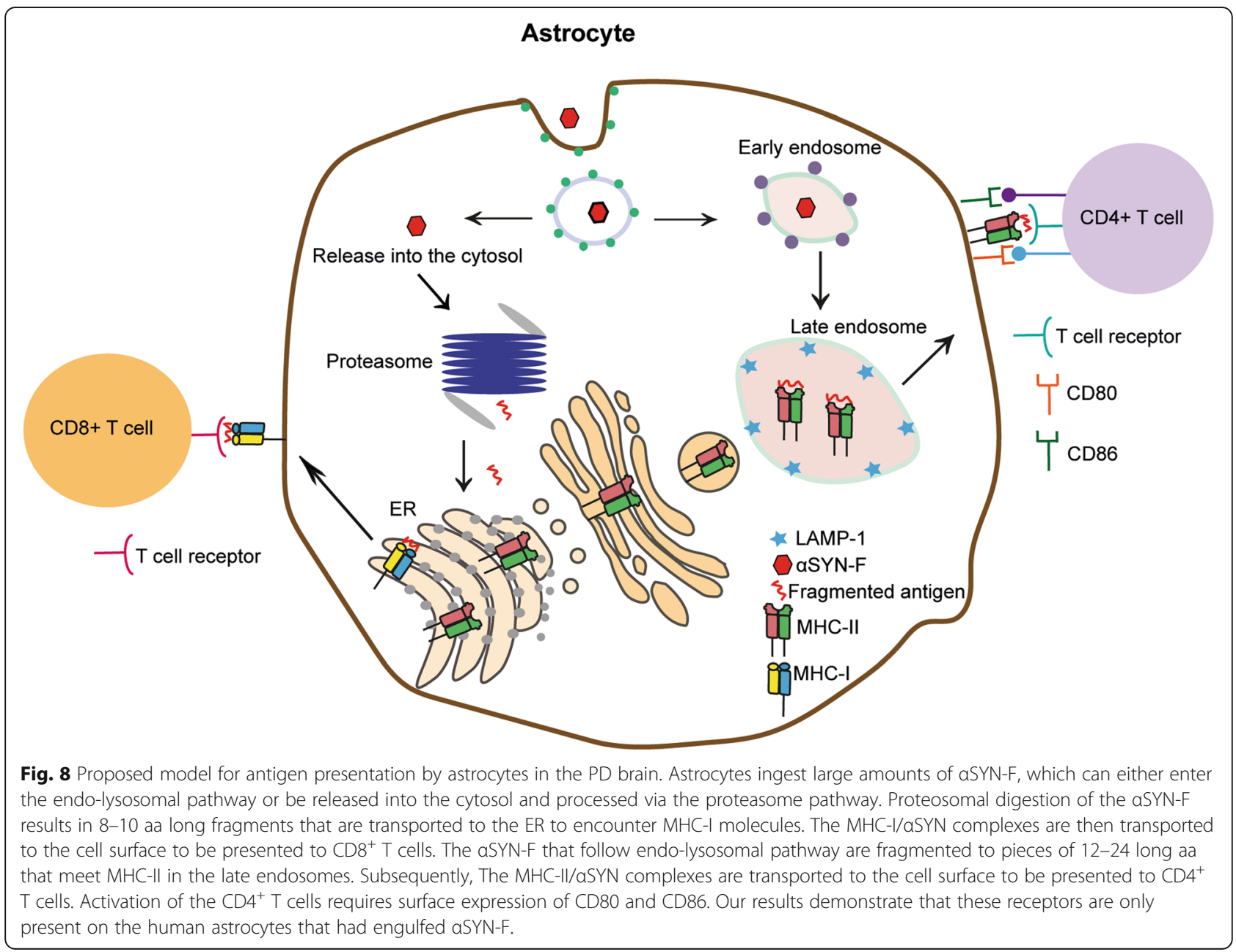


APCs have been suggested to transfer MHC-II molecules between each other via tunneling nanotubes [18]. We investigated whether MHC-II could be found in the tunneling nanotubes between the human astrocytes. Interestingly, not only MHC-II, but also $\alpha \mathrm{SYN} / \mathrm{MHC}$-II complexes were transferred from one astrocyte to another via the tunneling nanotubes. Hence, astrocytes can possibly transfer $\alpha \mathrm{SYN}$ deposits as an antigen bound to MHC-II to other astrocytes in the brain and thereby stimulate more astrocytes to become professional APCs.

\section{Conclusions}

Being the most numerous glial cell type in the central nervous system, astrocytes have great impact on brain homeostasis. Yet, their exact role in PD pathology remains elusive. Our histology and cell culture studies suggest that astrocytes have the potential to serve as major antigen-presenting cells in the PD brain. Following exposure to fibrillary $\alpha \mathrm{SYN}$, cultured human astrocytes, but not microglia, express the co-stimulatory molecules crucial for T-cell activation. Moreover, immunostaining of post mortem tissue confirms that MHC-II expressing astrocytes surround perivascular and parenchymal $\mathrm{CD} 4^{+}$ $\mathrm{T}$ cells in the PD brain. Finally, aggregates of $\alpha \mathrm{SYN}$ and MHC-II are transferred between astrocytes via tunneling nanotubes, suggesting a possible mechanism for spreading of $\alpha \mathrm{SYN}$-induced inflammation in the PD brain. In conclusion, our data indicate that astrocytes play an important role in antigen presentation and T-cell activation in the PD brain (Fig. 8), highlighting astrocytes as a promising therapeutic target in the context of chronic inflammation.

\section{Supplementary information}

Supplementary information accompanies this paper at https://doi.org/10. 1186/s12974-020-01776-7.

Additional file 1. MHC-II levels do not correlate with age in the analyzed material. Linear regression analysis on the MHC-II and the age in the PD group and in the control group demonstrate that there are no correlation between age and the expression of MHC-II in the material included in this study (61-84 years of age).

Additional file 2. Measurement of GLAST, GFAP and Iba1 in human PD and control brain sections. Integrated density of GLAST, GFAP and Iba1 was measured in mesencephalon sections of 10 PD and 10 control cases (a). Staining of GLAST and GFAP in mesencephalon revealed that these two astrocytic markers only overlap to some degree (b). Scale bar (b) = $20 \mu \mathrm{m}$.

Additional file 3. Human ES-derived astrocytes express astrocytic markers. Human astrocytes derived from embryonic stem cells express the astrocytic markers GFAP, ALDHL1, nestin, vimentin and GLAST. Scale bar $=20 \mu \mathrm{m}$

Additional file 4. Characterization of pre-formed aSYN fibrils. ThT assay demonstrated $\beta$-sheet structure of the aSYN-F (a). TEM further confirmed the $\beta$-sheet structure of the aSYN fibrils and the reduction in fibril size after sonication (b-c). Scale bars: (b) $=2 \mu \mathrm{m}$, (c) $=200 \mathrm{~nm}$.

Additional file 5. Astrocytes express PDL-1. When exposed to IFNY, astrocytes express increased levels of PDL-1. Scale bar $=20 \mu \mathrm{m}$.

\section{Abbreviations}

APC: Antigen-presenting cell; aSYN: Alpha-synuclein; CNTF: Ciliary neurotrophic factor; DC: Dendritic cell; ESC: Embryonic stem cell; GFAP: Glial fibrillary acidic protein; GLAST: Glutamate Aspartate transporter 1; Iba1: Ionized calcium-binding adaptor protein 1; IntDen: Integrated density; MHC: Major histocompatibility class; PD : Parkinson's disease; PFA: Paraformal dehyde; ThT: Thioflavin T; TSA: Tyramide signal amplification

\section{Acknowledgements}

We would like to thank Professor Irina Alafuzoff from Uppsala University for kindly providing us with human brain sections and Associate Professor

Laurent Roybon and Doctor Kaspar Russ from Lund University for providing us with human astrocytes. None of the authors has any conflicts of interest with the contents of this article.

\section{Authors' contributions}

JR designed the study, optimized and performed experiments, interpreted data, and wrote the manuscript; GF performed experiments, interpreted, data and wrote the manuscript; IS performed experiments, interpreted data, and wrote the manuscript; RM performed experiments and revised the manuscript; JB designed the study and wrote the manuscript; ME designed the study, interpreted data, and wrote the manuscript; LH designed the study, performed experiments, interpreted data, and wrote the manuscript; AE designed the study, interpreted data, coordinated the study, and wrote the manuscript. All authors have read and approved the final manuscript.

\section{Funding}

This study was supported by grants from the Swedish Research Council, the Swedish Parkinson Foundation, the Swedish Alzheimer Foundation, Åhlén Foundation, the Dementia Association Foundation, Olle Engkvist Foundation, Torsten Söderbergs Foundation, and the Swedish Brain Foundation.

\section{Availability of data and materials}

All data generated or analyzed during this study are included in this article.

\section{Ethics approval and consent to participate}

Brain sections from mesencephalon and striatum of 10 PD patients and 10 controls (Table 1) were used (kindly provided from Uppsala Biobank by Professor Irina Alafuzoff, ethical number 2012/494). Human adult microglia were isolated from the temporal lobe of three epilepsy patients undergoing surgery (ethical number ANTJ 1988/3).

\section{Consent for publication}

Not applicable.

\section{Competing interests}

The authors declare that they have no competing interests.

\section{Author details}

${ }^{1}$ Molecular Geriatrics, Department of Public Health and Caring Sciences/ Molecular Geriatrics, Rudbeck Laboratory, Uppsala University, SE-751 85 Uppsala, Sweden. '2Department of Immunology, Genetics and Pathology, Uppsala University, SE-751 85 Uppsala, Sweden. ${ }^{3}$ Neuroimmunology Unit, department of Neurology and Neurosurgery, Montreal Neurological Institute, McGill University, Montreal 3801, Canada.

Received: 11 July 2019 Accepted: 17 March 2020

Published online: 16 April 2020

\section{References}

1. Spillantini MG, Schmidt ML, Lee VM, Trojanowski JQ, Jakes R, Goedert M. Alpha-synuclein in Lewy bodies. Nature. 1997;388(6645):839-40.

2. Hirsch EC, Vyas S, Hunot S. Neuroinflammation in Parkinson's disease. Parkinsonism Relat Disord. 2012;18(Suppl 1):S210-2.

3. Sulzer D, Alcalay RN, Garretti F, Cote L, Kanter E, Agin-Liebes J, et al. T cells from patients with Parkinson's disease recognize a-synuclein peptides. Nature. 2017;546(7660):656-61.

4. Brochard V, Combadière B, Prigent A, Laouar Y, Perrin A, Beray-Berthat V, et al. Infiltration of CD4+ lymphocytes into the brain contributes to neurodegeneration in a mouse model of Parkinson disease. J Clin Invest. 2009;119(1):182-92. 
5. McGeer PL, Itagaki S, Akiyama H, McGeer EG. Rate of cell death in parkinsonism indicates active neuropathological process. Ann Neurol. 1988; 24(4):574-6.

6. Sommer A, Fadler T, Dorfmeister E, Hoffmann A-C, Xiang W, Winner B, et al. Infiltrating $T$ lymphocytes reduce myeloid phagocytosis activity in synucleinopathy model. J Neuroinflammation. 2016;13(1):174.

7. Sofroniew MV, Vinters HV. Astrocytes: biology and pathology. Acta Neuropathol (Berl). 2010;119(1):7-35.

8. Phatnani H, Maniatis T. Astrocytes in neurodegenerative disease. Cold Spring Harb Perspect Biol. 2015;7(6):a020628.

9. Pekny M, Wilhelmsson U, Pekna M. The dual role of astrocyte activation and reactive gliosis. Neurosci Lett. 2014;565:30-8.

10. Tu PH, Galvin JE, Baba M, Giasson B, Tomita T, Leight S, et al. Glial cytoplasmic inclusions in white matter oligodendrocytes of multiple system atrophy brains contain insoluble alpha-synuclein. Ann Neurol. 1998:44(3): 415-22

11. Terada S, Ishizu H, Yokota O, Tsuchiya K, Nakashima H, Ishihara T, et al. Glial involvement in diffuse Lewy body disease. Acta Neuropathol (Berl). 2003; 105(2):163-9.

12. Wakabayashi K, Hayashi S, Yoshimoto M, Kudo H, Takahashi H. NACP/alphasynuclein-positive filamentous inclusions in astrocytes and oligodendrocytes of Parkinson's disease brains. Acta Neuropathol (Berl). 2000;99(1):14-20.

13. Croisier E, Graeber MB. Glial degeneration and reactive gliosis in alphasynucleinopathies: the emerging concept of primary gliodegeneration. Acta Neuropathol (Berl). 2006;112(5):517-30.

14. Braak H, Sastre M, Del Tredici K. Development of alpha-synuclein immunoreactive astrocytes in the forebrain parallels stages of intraneuronal pathology in sporadic Parkinson's disease. Acta Neuropathol (Berl). 2007; 114(3):231-41.

15. Rostami J, Holmqvist S, Lindström V, Sigvardson J, Westermark GT, Ingelsson $M$, et al. Human astrocytes transfer aggregated alpha-synuclein via tunneling nanotubes. J Neurosci Off J Soc Neurosci. 2017;37(49):11835-53.

16. Loria F, Vargas JY, Bousset L, Syan S, Salles A, Melki R, et al. a-Synuclein transfer between neurons and astrocytes indicates that astrocytes play a role in degradation rather than in spreading. Acta Neuropathol (Berl). 2017 134(5):789-808.

17. Blum JS, Wearsch PA, Cresswell P. Pathways of antigen processing. Annu Rev Immunol. 2013:31:443-73.

18. Campana S, De Pasquale C, Carrega P, Ferlazzo G, Bonaccorsi I. Crossdressing: an alternative mechanism for antigen presentation. Immunol Lett. 2015;168(2):349-54.

19. Ford AL, Goodsall AL, Hickey WF, Sedgwick JD. Normal adult ramified microglia separated from other central nervous system macrophages by flow cytometric sorting. Phenotypic differences defined and direct ex vivo antigen presentation to myelin basic protein-reactive CD4+ T cells compared. J Immunol Baltim Md 1950. 1995;154(9):4309-21.

20. Carson MJ, Reilly CR, Sutcliffe JG, Lo D. Mature microglia resemble immature antigen-presenting cells. Glia. 1998;22(1):72-85.

21. Carson MJ, Sutcliffe JG, Campbell IL. Microglia stimulate naive T-cell differentiation without stimulating T-cell proliferation. J Neurosci Res. 1999; 55(1):127-34.

22. Holmqvist S, Brouwer M, Djelloul M, Diaz AG, Devine MJ, Hammarberg A, et al. Generation of human pluripotent stem cell reporter lines for the isolation of and reporting on astrocytes generated from ventral midbrain and ventral spinal cord neural progenitors. Stem Cell Res. 2015;15(1):203-20.

23. Durafourt BA, Moore CS, Blain M, Antel JP. Isolating, culturing, and polarizing primary human adult and fetal microglia. Methods Mol Biol Clifton NJ. 2013;1041:199-211.

24. Middeldorp J, Hol EM. GFAP in health and disease. Prog Neurobiol. 2011; 93(3):421-43.

25. Abounit S, Bousset L, Loria F, Zhu S, de Chaumont F, Pieri L, et al. Tunneling nanotubes spread fibrillar a-synuclein by intercellular trafficking of lysosomes. EMBO J. 2016;35(19):2120-38.

26. Song YJC, Halliday GM, Holton JL, Lashley T, O'Sullivan SS, McCann H, et al. Degeneration in different parkinsonian syndromes relates to astrocyte type and astrocyte protein expression. J Neuropathol Exp Neurol. 2009;68(10): 1073-83.

27. Prajeeth CK, Kronisch J, Khorooshi R, Knier B, Toft-Hansen H, Gudi V, et al. Effectors of Th1 and Th17 cells act on astrocytes and augment their neuroinflammatory properties. J Neuroinflammation. 2017:14(1):204.
28. Constantinescu CS, Tani M, Ransohoff RM, Wysocka M, Hilliard B, Fujioka T, et al. Astrocytes as antigen-presenting cells: expression of IL-12//L-23. J Neurochem. 2005;95(2):331-40.

29. Falcão AM, van Bruggen D, Marques S, Meijer M, Jäkel S, Agirre E, et al. Disease-specific oligodendrocyte lineage cells arise in multiple sclerosis. Nat Med. 2018;24(12):1837-44.

30. Zhu J, Paul WE. CD4 T cells: fates, functions, and faults. Blood. 2008;112(5): 1557-69.

31. Baba Y, Kuroiwa A, Uitti RJ, Wszolek ZK, Yamada T. Alterations of Tlymphocyte populations in Parkinson disease. Parkinsonism Relat Disord. 2005:11(8):493-8.

32. Niwa F, Kuriyama N, Nakagawa M, Imanishi J. Effects of peripheral lymphocyte subpopulations and the clinical correlation with Parkinson's disease. Geriatr Gerontol Int. 2012;12(1):102-7.

33. Chen S, Liu Y, Niu Y, Xu Y, Zhou Q, Xu X, et al. Increased abundance of myeloid-derived suppressor cells and Th17 cells in peripheral blood of newly-diagnosed Parkinson's disease patients. Neurosci Lett. 2017:648:21-5.

34. Falk K, Rötzschke O, Stevanović S, Jung G, Rammensee HG. Allele-specific motifs revealed by sequencing of self-peptides eluted from MHC molecules. Nature. 1991;351(6324):290-6.

35. Oueslati A, Fournier M, Lashuel HA. Role of post-translational modifications in modulating the structure, function and toxicity of alpha-synuclein: implications for Parkinson's disease pathogenesis and therapies. Prog Brain Res. 2010:183:115-45.

36. Oueslati A. Implication of alpha-synuclein phosphorylation at S129 in synucleinopathies: what have we learned in the last decade? J Park Dis. 2016;6(1):39-51.

37. Croisier E, Moran LB, Dexter DT, Pearce RKB, Graeber MB. Microglial inflammation in the parkinsonian substantia nigra: relationship to alphasynuclein deposition. J Neuroinflammation. 2005;2:14.

38. Verkhratsky A, Nedergaard M, Hertz L. Why are astrocytes important? Neurochem Res. 2015;40(2):389-401.

\section{Publisher's Note}

Springer Nature remains neutral with regard to jurisdictional claims in published maps and institutional affiliations.
Ready to submit your research? Choose BMC and benefit from:

- fast, convenient online submission

- thorough peer review by experienced researchers in your field

- rapid publication on acceptance

- support for research data, including large and complex data types

- gold Open Access which fosters wider collaboration and increased citations

- maximum visibility for your research: over $100 \mathrm{M}$ website views per year

At $\mathrm{BMC}$, research is always in progress.

Learn more biomedcentral.com/submissions 